\title{
Basilic vein transposition for unsuitable upper arm hemodialysis needle access segment may attenuate concurrent hand ischemia
}

Citation for published version (APA):

Gerrickens, M. W. M., Vaes, R. H. D., Govaert, B., Teijink, J. A. W., \& Scheltinga, M. R. (2018). Basilic vein transposition for unsuitable upper arm hemodialysis needle access segment may attenuate concurrent hand ischemia. Hemodialysis international, 22(3), 335-341. https://doi.org/10.1111/hdi.12654

Document status and date:

Published: 01/07/2018

DOI:

10.1111/hdi.12654

Document Version:

Publisher's PDF, also known as Version of record

Document license:

Taverne

Please check the document version of this publication:

- A submitted manuscript is the version of the article upon submission and before peer-review. There can be important differences between the submitted version and the official published version of record.

People interested in the research are advised to contact the author for the final version of the publication, or visit the DOI to the publisher's website.

- The final author version and the galley proof are versions of the publication after peer review.

- The final published version features the final layout of the paper including the volume, issue and page numbers.

Link to publication

\footnotetext{
General rights rights.

- You may freely distribute the URL identifying the publication in the public portal. please follow below link for the End User Agreement:

www.umlib.nl/taverne-license

Take down policy

If you believe that this document breaches copyright please contact us at:

repository@maastrichtuniversity.nl

providing details and we will investigate your claim.
}

Copyright and moral rights for the publications made accessible in the public portal are retained by the authors and/or other copyright owners and it is a condition of accessing publications that users recognise and abide by the legal requirements associated with these

- Users may download and print one copy of any publication from the public portal for the purpose of private study or research.

- You may not further distribute the material or use it for any profit-making activity or commercial gain

If the publication is distributed under the terms of Article $25 \mathrm{fa}$ of the Dutch Copyright Act, indicated by the "Taverne" license above, 


\title{
Original Article
}

Access

\section{Basilic vein transposition for unsuitable upper arm hemodialysis needle access segment may attenuate concurrent hand ischemia}

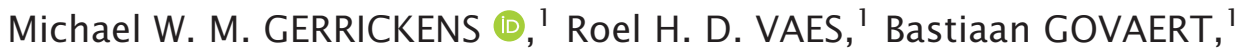 \\ Joep A. W. TEIJINK, ${ }^{2}$ Marc R. SCHELTINGA ${ }^{1}$ \\ ${ }^{1}$ Department of Surgery, Máxima Medical Centre, Veldhoven, The Netherlands; ${ }^{2}$ Department of \\ Surgery, Catharina Hospital, Eindhoven, The Netherlands
}

\begin{abstract}
Introduction: Some hemodialysis patients with a brachial arteriovenous fistula (AVF) have an unsuitable upper arm needle access segment (NAS) necessitating basilic vein transposition (BVT). It was frequently observed that a portion of these patients spontaneously experienced a warmer and less painful dialysis hand after BVT. Aim of this study was to determine whether BVT for an inadequate NAS attenuated hemodialysis access-induced distal ischemia in patients with a brachial AVF.

Methods: Patients with a brachial AVF and an unsuitable NAS also reporting hand ischemia and scheduled to undergo BVT between 2005 and 2016 in a single facility were studied. Hand ischemia was graded as proposed in a 2016 consensus meeting. Hand ischemic questionnaire (HIQ-) scores ( 0 points, no ischemia-500 points, maximal ischemia), digital brachial index (DBI, ischemia $<0.6$ ) and access flow $(\mathrm{mL} / \mathrm{min})$ before and after BVT were compared. The cephalic vein and all side branches of the basilic vein were ligated during the BVT.

Findings: Ten patients were studied ( 8 males, 61 [54-75] years). BVT was performed 8 [4-10] months following the initial AVF construction. HIQ-scores dropped from 220 [71-285] to 9 [0-78] $(P=0.043)$ postoperatively, whereas $\mathrm{DBI}$ increased from 0.51 [0.39-0.67] to 0.85 [0.68-0.97] $(\mathrm{P}=0.012)$. $\mathrm{DBI}$ and $\mathrm{HIQ}$-scores were inversely correlated $\left(R^{2}=71 \%, \mathrm{P}=0.001\right)$. Access flows dropped significantly (Flow pre $1120 \mathrm{~mL} / \mathrm{min}$ [1100-2300] vs. Flow post $700 \mathrm{~mL} / \mathrm{min}$ [600-1760]; $\mathrm{P}=0.018$ ). Surgery-associated complications were absent and dialysis continued uninterruptedly. Eight patients reported total recovery from hand ischemia six weeks postoperatively.

Discussion: Basilic vein transposition for an unsuitable upper arm needle access segment may attenuate hand ischemia in patients with a brachial AVF previously reporting hemodialysis accessinduced distal ischemia.
\end{abstract}

Key words: Basilic vein transposition, digital brachial index, hand ischemia, hemodialysis access-induced distal ischemia

Correspondence to: M. W. M. Gerrickens, Department of Surgery, Máxima Medical Centre, de Run 4600, Veldhoven 5504 DB, The Netherlands. E-mail: vascular.resurge@mmc.nl Conflict of Interest: The authors have no conflict of interest. Disclosure of grants or other funding: None.

\section{INTRODUCTION}

Due to aging populations and associated higher incidences of diabetes mellitus and atherosclerosis, the rate of brachial artery-based arteriovenous fistulas (AVFs) in 
patients requiring hemodialysis (HD) will rise at the expense of radial artery-based AVFs. ${ }^{1}$ The upper arm needle access segment (NAS) of some brachial artery-based AVFs does not mature adequately and may remain too short, too deep, or too curved precluding two needle placement. Upper arm cannulation options may then be optimized by a basilic vein transposition (BVT).,3

Over time, a brachial artery-based AVF may lead to complications including hand ischemia (hemodialysis accessinduced distal ischemia [HAIDI]). ${ }^{4}$ Several studies suggest that HAIDI is caused by a loss in perfusion pressure along the arterial heart-arm axis. ${ }^{5,6}$ Diagnostic efforts are, therefore, directed toward identifying sources of blood pressure loss. If inflow arteries are patent, HAIDI may in part be caused by the arteriovenous anastomosis' pressure sink and/or lower arm atherosclerosis. ${ }^{7}$ Recent studies demonstrated that patent venous side branches (SB) of a brachial artery-based AVF also may lead to blood pressure loss and may contribute to hand ischemia. Moreover, side branch ligation (SBL) mitigated signs and symptoms of HAIDI. ${ }^{8,9}$

A BVT procedure includes ligation of the basilic vein's SBs as well as the cephalic vein. We incidentally observed that patients who underwent a BVT for an insufficiently matured NAS spontaneously reported a warmer and less painful dialysis hand after the operation. Aim of the study was to determine whether BVT attenuated signs and symptoms of hand ischemia in patients having an unsuitable upper arm NAS who were also reporting coincident HAIDI.

\section{MATERIALS AND METHODS}

\section{General information}

At present, approximately 110 patients receive $\mathrm{HD}$ in Máxima Medical Centre, Veldhoven, The Netherlands. Furthermore, about 100 AVF-related operations are performed annually. If construction of a radio-cephalic (RC-) AVF is deemed impossible as judged by preoperative Duplex imaging, our preferred technique is the creation of a brachial artery-based AVF termed a Gracz fistula. This type of AVF entails mobilizing of the median cubital vein or a deep perforating venous branch that is subsequently connected to the brachial artery some $2 \mathrm{~cm}$ distal to the elbow fold. Using this technique, outflow is usually via upper arm cephalic and basilic veins and their SBs. ${ }^{10,11}$

\section{Inadequate NAS and HAIDI}

Access flow of our HD population is standardly measured in duplicate every two months as suggested by KDOQI ${ }^{12}$ using a standard two-needle dilution technique (HD03, Transonic Systems Inc, NY, USA). Each patient with structurally complicated HD sessions is discussed in a weekly multidisciplinary meeting attended by a nephrologist, vascular surgeon, interventional radiologist, vascular laboratory technician, and nurses of the shunt team. If the upper arm access segment of an elbow-based AVF is considered inadequate for placement of two needles leading to a suboptimal dialysis, a Duplex is performed for access imaging and flow measurement. Conversion to a BVT is discussed if the basilic vein is considered of sufficient diameter $(>3-4 \mathrm{~mm})$ and length $(>10 \mathrm{~cm})$.

The multidisciplinary team has a special interest in the management of hand ischemia. Each patient reporting symptoms possibly associated with ischemia is also discussed in the weekly meeting. If the history suggests HAIDI (pain, cramps, coldness, loss of strength, and/or diminished sensibility), a questionnaire scores symptomatology (hand ischemic questionnaire [HIQ]). Scores range from 0 (no symptoms associated with ischemia) to 500 (maximal symptoms of ischemia). ${ }^{4}$ Several studies have indicated that a HIQ-score reflects grade of ischemia and may be used to determine efficacy of remedial surgery. $4,6,8,9,13,14$ For instance, access outflow banding diminished HIQ-scores from $153 \pm 33$ to $42 \pm 15$ whereas ischemia was largely abolished. ${ }^{13}$ Moreover, SBL in another population of HAIDI patients decreased HIQscores from $184 \pm 21$ to $60 \pm 15 .^{9}$ Conversely, HIQscores in a random HD-population not reporting hand ischemia were predictably $<50$ using this 0 - to 500 -point scale. $^{15}$

If HAIDI is suspected on the basis of history and HIQscores, a physical examination at the outpatient vascular department is performed including hand inspection and radial artery palpation. Compression of upper arm cephalic and basilic vein is performed to test reversibility of ischemia. An index finger plethysmography with and without AVF compression is executed (Vasoguard Nicolet $8 \mathrm{MHz}$, Scimet, Bristol, UK). A $<50 \mathrm{mmHg}$ finger pressure (Pdig) or a $<0.6$ digital brachial index (DBI) are accepted cut-off points of hand ischemia. ${ }^{16-18}$ The degree of HAIDI was scored as advised in a recent consensus document (supplementary table 1). ${ }^{19}$ Additional imaging using a Seldinger or MR-angiography is indicated if patients suffered from a grade $2 \mathrm{~b}, 3$, or 4 HAIDI, unless an arterial stenosis is deemed highly unlikely as in very young HD-patients.

Some patients with a brachial AVF having an unsuitable upper arm NAS also report symptoms of HAIDI. Patients were included in the present study if they harbored a brachial artery-based AVF, if they had an 

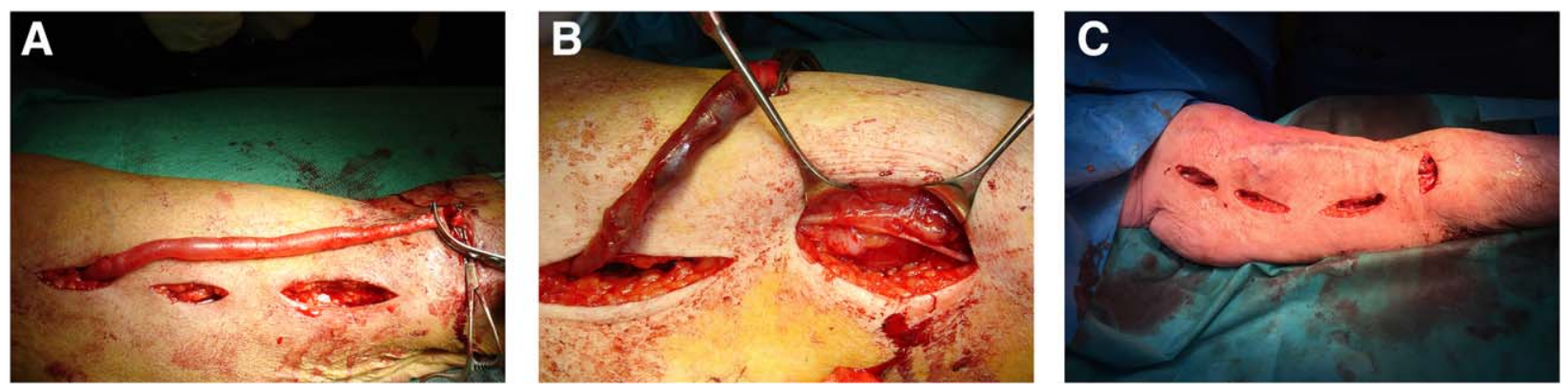

Figure 1 (a) Basilic vein transposition procedure. The upper arm basilic vein is disconnected from the original anastomosis and freed from its surroundings using three separate incisions. (b) The medial brachial cutaneous nerve is located in close relation to the basilic vein. (c) The vein is rerouted superficially along the anterolateral aspect of the biceps muscle and reanastomosed. [Color figure can be viewed at wileyonlinelibrary.com]

unsuitable NAS—defined as repetitive faulty and problematic two needle cannulation due too inadequate length, excessive depth, or tortuosity as deemed by the nurses of the shunt team and discussed in the multidisciplinary team - that would benefit from a BVT, and if they suffered from at minimal grade $2 a$ HAIDI. They were excluded if there were signs of impaired mental capacity or a language barrier or if a simultaneous additional (endo) vascular procedure for HAIDI was conducted. Patients were informed on the nature of the operative procedure and consented to its specifics verbally and in writing. Our ethics committee deemed that evaluation of the study protocol was not necessary, since the present analysis was considered auditing of surgical results and evaluation of patient-reported outcome measures.

\section{Operative protocol}

Each patient was operated under general anaesthesia using a standard protocol. Serial monitoring of finger pressures under strict sterile conditions was performed in patients suffering from a minimal $2 b$ HAIDI (Pdig in mmHg, index finger of the HD-hand; VasoGuard Nicolet, $8 \mathrm{Mhz}$, Scimed Ltd, Bristol, UK). Serial measurements of heart rate (HR, beats/min) and blood pressure (systolic blood pressure, diastolic blood pressure, $\mathrm{mmHg}$ ) were obtained from the contralateral arm at regular intervals via an online electrocardiogram and a sphygmomanometer. The basilic vein was disconnected from the arterial anastomosis in the elbow area and dissected via 2-3 separate incisions (Figure 1a). All of its SBs including the distal basilic vein, perforating veins and upper arm cephalic vein were ligated. Special care was taken not to damage the accompanying medial brachial cutaneous nerve (Figure 1b). The basilic vein was superficially rerouted along the anterolateral aspect of the biceps muscle and re-anastomosed to the brachial artery
(Figure 1c). Intraoperative success was determined by a combination of palpable thrill, increased radial artery pulsations, a warmer hand, and increase in DBI. Single access needling was allowed immediately on the day of surgery or on the first postoperative day followed by a two-needle regimen from Day 14 on.

\section{Follow-up and definitions}

A history and physical examination were obtained regarding signs and symptoms of hand ischemia in each patient at the outpatient vascular department approximately six weeks postoperatively. Access flows and HIQ-scores were measured during the first three months after BVT. Data were recorded from local electronic patient files (EZIS 5.2, ChipSoft B.V., Amsterdam, the Netherlands). Values of Pdig that were faulty or not obtainable due to incompressible digital arteries were omitted from analysis. Questionnaires that were incompletely filled out by the patient and HIQ-scores that were considered extreme defined as exceeding three times the interquartile rangewhile not congruent with history or findings at physical examination, were also deleted.

Statistical analyses were performed using SPSS version 24.0 (SPSS Inc., Chicago, IL, USA). Parameters were tested for normality. A Wilcoxon-signed rank test was used to determine the effect of BVT on DBI, HIQ-scores and access flow. Possible correlations between DBI and HIQ-scores were analysed using linear regression. Results where expressed as median (interquartile range). A $P$ value $<0.05$ was considered significant.

\section{RESULTS}

During the 11-year observation period, 60 BVTs were performed in our institution. In 21 patients, the 
Table 1 Demographics of patients undergoing basilic vein transposition (BVT) for an unsuitable upper arm needle access segment and concurrent hand ischemia.

\begin{tabular}{lc}
\hline $\mathrm{N}$ & 10 \\
Age (years, median \pm interquartile ranges) & $61[54-75]$ \\
Gender (male/female) & $8 / 2$ \\
Diabetes mellitus (\%) & $4(40)$ \\
Peripheral arterial occlusive disease (\%) & $4(40)$ \\
Hypertension (\%) & $7(70)$ \\
Coronary artery disease (\%) & $3(30)$ \\
AVF (Gracz/Brachiobasilic) & $9 / 1$ \\
Time between AVF construction & $8[4-10]$ \\
$\quad$ and BVT (months, median \pm & \\
$\quad$ interquartile ranges) & \\
HAIDI grade (2a/2b/3/4) & $2 / 3 / 5 / 0$ \\
\hline
\end{tabular}

$\mathrm{AVF}=$ arteriovenous $\quad$ fistula $; \quad$ HAIDI $=$ hemodialysis $\quad$ access induced distal ischemia.

indication for BVT was an inadequate NAS after earlier elbow AVF-construction. Eleven patients reported coincident hand ischemia and thus were eligible for the present study. One patient was excluded because of an additional banding procedure intraoperatively. Therefore, the study population consisted of ten patients (median age 61 years, 8 males, Table 1). In all ten, preoperative vein mapping precluded construction of a RC-AVF due to inadequate vein diameter necessitating the construction of brachialartery-based AVF. Eight of these ten patients currently used their access for HD. However, one patient preferred dialysis via central venous lines due to fear of needles whereas the tenth patient was still in a predialysis stage.

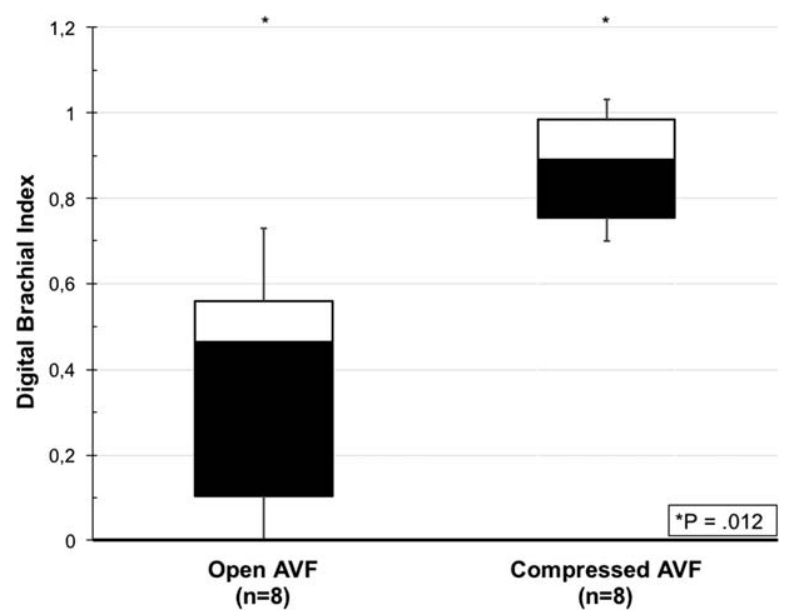

Figure 2 Digital Brachial Index (DBI) in patients with an unsuitable upper arm needle access segment and hand ischemia, open vs. compressed arteriovenous fistula (AVF).
Prior to BVT, compression of the access' outflow demonstrated more prominent radial artery pulsations suggesting reversible hand ischemia in all ten patients. Reversibility of ischemia was likely as manual compression increased DBI well above the ischemic threshold of $0.6\left(\mathrm{n}=8, \mathrm{DBI}_{\text {open }} 0.47,[0.10-0.56]\right.$ vs. $\mathrm{DBI}_{\text {compressed }}$ 0.89, [0.76-0.99], $\mathrm{P}=0.012$, missing $\mathrm{n}=2$; Figure 2).

No patient had evidence of arterial inflow stenosis on Duplex sonography $(n=8)$ or Seldinger angiography ( $n=6$; HAIDI 2a $n=2$, rejected Seldinger $n=1$, stenosis highly unlikely due to young age $\mathrm{n}=1$ ). Furthermore, Duplex analysis $(n=8)$ did not demonstrate a steal phenomenon distal to the brachial artery anastomosis as defined by retrograde flow in ulnar or radial artery forearm arteries in seven patients. However, one patient suffering from HAIDI $2 \mathrm{a}$ showed alternating flow directions (retrograde at end of diastole, antegrade in remainder of cycle) in both ulnar and radial arteries.

Following BVT, DBI values increased significantly ( $\mathrm{n}=8, \mathrm{DBI}_{\text {pre }} 0.51[0.39-0.67]$ vs. DBI $\mathrm{Dost} 0.85,[0.68-$ 0.97], $\mathrm{P}=0.012$, intraoperative measurements; Figure 3). Moreover, access flows decreased slightly (Flow $1120 \mathrm{~mL} / \mathrm{min}$ [1100-2300] vs. Flow ${ }_{\text {post }} 700 \mathrm{~mL} / \mathrm{min}$ [600-1760]; $\mathrm{P}=0.018 ; \mathrm{N}=7$, missing $\mathrm{n}=3$ ). Interestingly, DBI values and HIQ-scores were inversely correlated $\left(\mathrm{n}=12, \quad \mathrm{R}^{2}=71 \%, \mathrm{P}=0.001 ;\right.$ preoperative measurements $n=7$, postoperative measurements $n=5$, missing $\mathrm{n}=8$; Figure 4)

All eight patients resumed HD-sessions using one needle cannulation after BVT, either on the same or on the first postoperative day. Uncomplicated two needle HDregimens were possible from Day 14 on in all. Patient nine

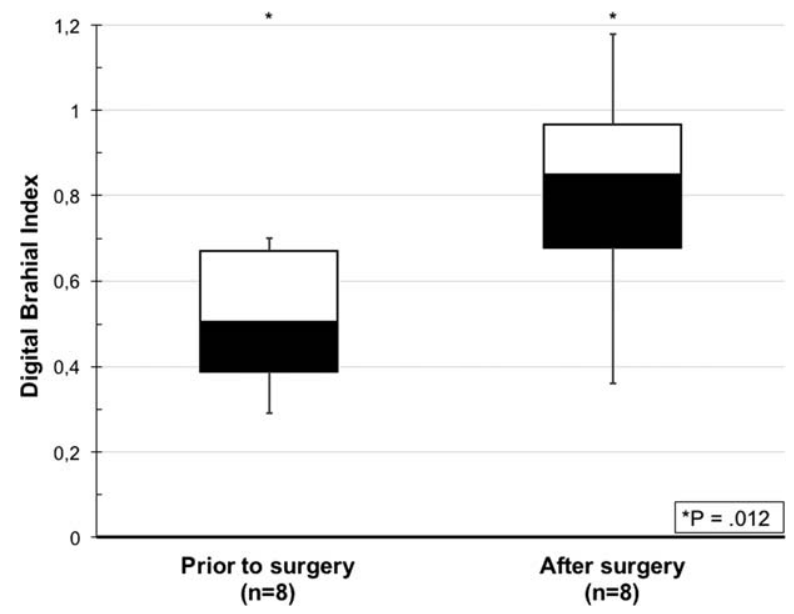

Figure 3 Digital brachial index (DBI) prior to and after basilic vein transposition for inadequate needle access segment. 


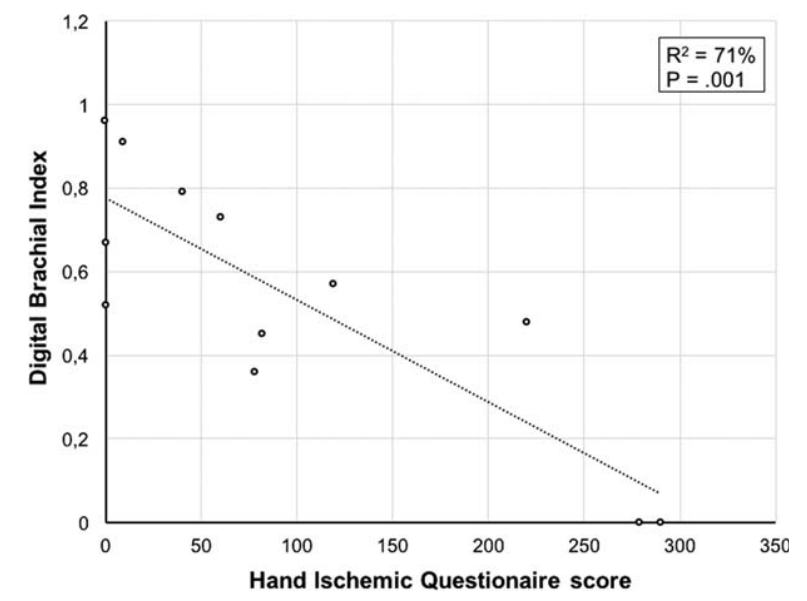

Figure 4 Correlation between hand ischemic questionnaire score and digital brachial index (Preoperative $\mathrm{n}=7$, postoperative $n=5$, missing $n=8$ ).

continued HD via central venous lines duo to persisting fear of needles while the tenth patient remained in the predialysis tract. Immediate postoperative complications such as wound infection, access thrombosis, or requirement of temporary central venous lines were not observed. One patient developed a pseudoaneurysm of the basilic vein in the presence of several puncture holes two weeks postoperatively necessitating successful surgery with uninterrupted dialysis. A percutaneous transluminal angioplasty was required in three patients because of access flow reduction due to a stenosis in the outflow tract within three months postsurgery followed by uncomplicated dialysis. Tissue loss due to previous hand ischemia was absent whereas additional surgery for recurrent HAIDI was not required.

At the six weeks follow-up, eight patients reported total recovery from ischemia, whereas the ninth patient experienced an improvement. The tenth patient stated that BVT did not affect his hand ischemia, although specific history and physical examination suggested no signs of ischemia anymore. After renal transplantation, this patient demanded AVF-ligation. Overall HIQ-scores had dropped significantly (HIQ pre 220 [71-285] vs. HIQ post 9 [0-78], $\mathrm{P}=0.043 ; \mathrm{n}=5$, incomplete questionnaire $\mathrm{n}=1$, absent data $n=3$, extreme value without clinical evidence of ischemia $n=1$ ). A separate analysis of the five cardinal symptoms associated with HAIDI demonstrated that pain was absent after the operation (Pain ${ }_{\text {pre }} 42$ [18-75] vs. Pain $\left._{\text {post }}, \quad 0 \quad[0-0], \quad P=0.043\right)$. Coldness, sensibility change, and loss of strength also diminished although statistical significance was not attained (Coldness pre 49 [2-67] vs. Coldness post $_{0}$ [0-0], P =0.068; Diminished sensibility $_{\text {pre }} 56$ [45-70] vs. Diminished sensibility post $_{0}$
[0-25], P = 0.066; Loss of strength ${ }_{\text {pre }} 50$ [0-65] vs. Loss of strength ${ }_{\text {post }} 0$ [0-35], P=0.102). Cramps were not reported by any of the patients before or after BVT.

\section{DISCUSSION}

Several surgical techniques for the treatment of an inadequate upper arm NAS in the presence of a brachial arterybased AVF are currently available. For example, suctionassisted lipectomy may lead to cephalic vein superficialization and easier puncturing in obese patients. ${ }^{20}$ Furthermore, elevation and stretching procedures may effectively treat excessive depth and tortuosity of upper arm veins of a brachial artery-based AVF. However, cephalic vein cannulation in these populations is advised not earlier than three to six weeks after these procedures due to issues of wound healing and insufficient arterialization. ${ }^{21,22}$ Several studies on two-step BVT procedures show that cannulation was not performed earlier than four to seven weeks after the transposition step. ${ }^{23,24}$ The BVTs in the current study can be regarded as delayed two-step procedures and the results indicate that a transposed basilic vein is safely cannulated from day one on precluding the use of temporary lines.

Rates of complications associated with autologous elbow AVFs such as hand ischemia (HAIDI) are expected to rise. ${ }^{4}$ Accepted invasive therapies for HAIDI include proximalization of arterial inflow, revision using distal inflow or distal revascularisation and interval ligation but these techniques require an extensive operative dissection. However, a minimally invasive technique of ligation of patent venous access SBs was also found to attenuate symptoms of hand ischemia in two recent studies $^{8,9}$ as did coil embolization in another study. ${ }^{25}$ A BVT procedure that is popularized for patients with an insufficient upper arm NAS may in essence be regarded as an extended version of SB ligation. Surely, the cephalic vein being a SB of the access itself, as well as all of the basilic vein's SBs are tied off during this operative procedure.

A comparison of HAIDI rates of several brachial arterybased AVFs including brachiobasilic, brachiocephalic, and Gracz was never performed. Intuitively one might speculate that a dual outflow tract of both a cephalic and a basilic vein as in Gracz-AVF leads to a higher risk of hand ischemia. In one retrospective study on brachial artery-based AVFs, $65 \%$ of patients that developed hand ischemia harbored a Gracz-type fistula compared to $41 \%$ of patients without ischemic complaints. ${ }^{26}$ Interestingly, in one study on SB ligation, isolated ligation of the basilic vein sufficiently increased intraoperative DBI in only one patient whereas ligation of additional SBs was required in four patients. ${ }^{8}$ As both cephalic vein as well as basilic 
vein SBs were ligated, the present study does not allow for the identification of the definite cause of the ischemia. It may also be that recovery from ischemia, apart from $\mathrm{SBL}$, is due to the creation of a possibly smaller anastomosis. However, the width of the new arteriovenous anastomosis was not measured in the present study

A diagnosis of hand ischemia due to an HD-access is suspected on specifics of the patient's history. ${ }^{27,28}$ Pain, coldness and altered skin sensation in the ipsilateral hand as well as diminished strength and muscle cramps are often reported. ${ }^{29,30}$ Moreover, these subjective symptoms may be provoked during HD as systemic blood pressure and peripheral perfusion pressures drop toward the end of a HD-session. ${ }^{15}$ Pain in the affected limb that occurs or aggravates during HD can be a hallmark of impending ischemia and should never be ignored. ${ }^{31}$ The use of a HIQ allows for quantification of the five cardinal symptoms associated with hand ischemia., ${ }^{4,9,13-15}$ Interestingly, HIQ-scores and digital brachial indices, the latter generally accepted as the only parameter objectively reflecting hand ischemia, were inversely related underscoring the potential validity of a HIQ. It is probably worthwhile to standardly complete a HIQ in patients possibly suffering from HAIDI allowing for a comparison of HAIDI-rates in dialysis populations and efficacy of flow reducing therapies.

The role of a physical examination is pivotal in the diagnosis of hand ischemia. Pallor, muscle atrophy, and ulcers may be observed. ${ }^{18}$ Absent or weak radial artery pulsations in presence of these objective signs, also point toward HAIDI. If manually compressing the AVF's outflow results in more prominent radial artery pulsations whereas coldness subjectively diminishes, reversibility of ischemia is likely. ${ }^{5}$ In the current study, radial artery pulsations returned or were stronger after manual access compression whereas finger pressures increased significantly prior to BVT. If this were not the case, however, it must be questioned whether BVT or other flow reducing techniques are successful. Prior to embarking on any invasive surgical therapy, lower arm and hand vasculature require visualization using a selective Seldinger angiography with compressed AVF outflow. It is highly questionable whether (minimally) invasive therapy is beneficial if severe lower arm and hand atherosclerosis is demonstrated following imaging.

May BVT play a role in the armamentarium of therapies for HAIDI? Recent studies on SB ligation in hand ischemia hypothesized that it might be worthwhile to preoperatively determine flow in all venous outflow tracts of an AVF in combination with finger plethysmography. ${ }^{89}$ If flow in one or more SB's is present as suggested by a thrill using physical examination or by a hand held Doppler system, the magnitude of flow may be quantified using Duplex analysis. If total flow over SBs including the basilic vein is substantial and the cephalic vein is suitable for needling, SB ligation might be a simple first line treatment. Flow rates of the basilic vein and its SBs were not standardly determined in the present population. However, the combined findings of patient history (symptoms of HAIDI), physical examination (too short upper arm NAS, weak radial artery pulsations), imaging (plethysmography, $\mathrm{DBI}<0.6$ with open access, $>0.6$ following access compression; Duplex, flow in basilic vein and in its SBs) may aid in predicting whether a beneficial effect on hand ischemia is to be expected in patients requiring BVT. The present study also demonstrates that monitoring DBI during the operation is an important predictor of the efficacy of BVT in HAIDI.

This study suffers from potential limitations including small sample size, incomplete datasets, a short follow-up period and absence of a control group. Patients that rejected invasive surgery were not registered possibly causing selection bias. Furthermore, the majority of the patients harbored a Gracz-type fistula, which might make the results less applicable for other types of brachialartery-based access. However, it must be appreciated that the aim of the study was to prove the validity of the concept of a BVT in the treatment of patients with hand ischemia. In conclusion, BVT in HD patients with an unsuitable upper arm NAS in presence of a brachial AVF may attenuate signs and symptoms of hand ischemia.

Manuscript received November 2017.

\section{REFERENCES}

1 Tordoir JH, Bode AS, van Loon MM. Preferred strategy for hemodialysis access creation in elderly patients. Eur J Vasc Endovasc Surg. 2015; 49:738-743.

2 Inkollu S, Wellen J, Beller Z, Zhang T, Vachharajani $\mathrm{N}$, Shenoy S. Successful use of minimal incision superficialization technique for arteriovenous fistula maturation. J Vasc Surg. 2016; 63:1018-1025.

3 Lee Y, Song D, Kim MJ, Yun SC. Upper arm Basilic vein transposition for hemodialysis: A single center study for 300 cases. Vasc Specialist Int. 2016; 32:51-56.

4 van Hoek F, Scheltinga MR, Kouwenberg I, Moret KE, Beerenhout $\mathrm{CH}$, Tordoir JH. Steal in hemodialysis patients depends on type of vascular access. Eur J Vasc Endovasc Surg. 2006; 32:710-717.

5 Scheltinga MR, Bruijninckx CM. Haemodialysis accessinduced distal ischaemia (HAIDI) is caused by locoregional hypotension but not by steal. Eur J Vasc Endovasc Surg. 2012; 43:218-223. 
6 Vaes RH, Tordoir JH, Scheltinga MR. Blood flow dynamics in patients with hemodialysis access-induced hand ischemia. J Vasc Surg. 2013; 58:446-451 el.

7 Wixon CL, Hughes JD, Mills JL. Understanding strategies for the treatment of ischemic steal syndrome after hemodialysis access. J Am Coll Surg. 2000; 191:301-310.

8 Vaes RH, Scheltinga MR. Side branch ligation for haemodialysis-access-induced distal ischaemia. Eur J Vasc Endovasc Surg. 2012; 44:452-456.

9 Vaes RH, Wouda R, Teijink JA, Scheltinga MR. Venous side branch ligation as a first step treatment for haemodialysis access induced hand ischaemia: Effects on access flow volume and digital perfusion. Eur J Vasc Endovasc Surg. 2015; 50:810-814.

10 Gracz KC, Ing TS, Soung LS, Armbruster KF, Seim SK, Merkel FK. Proximal forearm fistula for maintenance hemodialysis. Kidney Int. 1977; 11:71-75.

11 Bender MH, Bruyninckx CM, Gerlag PG. The Gracz arteriovenous fistula evaluated: Results of the brachiocephalic elbow fistula in haemodialysis angio-access. Eur J Vasc Endovasc Surg. 1995; 10:294-297.

12 National Kidney Foundation KDWG. KDOQI clinical practice guidelines and clinical practice recommendations for 2006 updates: Hemodialysis adequacy, peritoneal dialysis adequacy and vascular access. Am J Kidney Dis. 2006; 48:S1-S322.

13 van Hoek F, Scheltinga M, Luirink M, Pasmans $H$, Beerenhout C. Banding of hemodialysis access to treat hand ischemia or cardiac overload. Semin Dial. 2009; 22:204-208.

14 Vaes RHD, Scheltinga MR. Resolution of severe haemodialysis access-induced distal Ischaemia using a femoro-axillary bypass graft. EJVES. 2011; 22: e61-ee63.

15 Van Hoek F, Scheltinga MR, Houterman S, Beerenhout $\mathrm{CH}$. Haemodialysis decreases finger pressures independent of artificial kidney blood flow. Nephrology (Carlton). 2009; 15:555-559.

16 Goff CD, Sato DT, Bloch PH. Steal syndrome complicating hemodialysis access procedures: Can it be predicted? Ann Vasc Surg. 2000; 14:138-144.

17 Papasavas PK, Reifsnyder T, Birdas TJ, Caushaj PF, Leers S. Prediction of arteriovenous access steal syndrome utilizing digital pressure measurements. Vasc Endovascular Surg. 2003; 37:179-184.

18 van Hoek F, Scheltinga MR, Luirink M, Raaymakers LC, van Pul C, Beerenhout CH. Access flow, venous saturation, and digital pressures in hemodialysis. J Vasc Surg. 2007; 45:968-973.

19 Inston N, Schanzer H, Widmer M, et al. Arteriovenous access ischemic steal (AVAIS) in haemodialysis: A consensus from the Charing Cross Vascular Access Masterclass 2016. J Vasc Access. 2017; 18:3-12.
20 Krochmal DJ, Rebecca AM, Kalkbrenner KA, et al. Superficialization of deep arteriovenous access procedures in obese patients using suction-assisted lipectomy: A novel approach. Can J Plast Surg. 2010; 18:25-27.

21 Cull DL, Taylor SM, Carsten CG, et al. The fistula elevation procedure: a valuable technique for maximizing arteriovenous fistula utilization. Ann Vasc Surg. 2002; 16:84-88.

22 Bronder CM, Cull DL, Kuper SG, et al. Fistula elevation procedure: Experience with 295 consecutive cases during a 7-year period. J Am Coll Surg. 2008; 206: 1076-1081, discussion 81-82.

23 Hossny A. Brachiobasilic arteriovenous fistula: Different surgical techniques and their effects on fistula patency and dialysis-related complications. J Vasc Surg. 2003; 37:821-826.

24 Kakkos SK, Tsolakis IA, Papadoulas SI, et al. Randomized controlled trial comparing primary and staged basilic vein transposition. Front Surg. 2015; 2:14.

25 Kariya S, Tanigawa N, Kojima H, et al. Transcatheter coil embolization for steal syndrome in patients with hemodialysis access. Acta Radiol. 2009; 50:28-33.

26 Rocha A, Silva F, Queiros J, Malheiro J, Cabrita A. Predictors of steal syndrome in hemodialysis patients. Hemodial Int. 2012; 16:539-544.

27 Padberg FT Jr, Calligaro KD, Sidawy AN. Complications of arteriovenous hemodialysis access: recognition and management. J Vasc Surg. 2008; 48:S55-S80.

28 Modaghegh MH, Roudsari B, Hafezi S. Digital pressure and oxygen saturation measurements in the diagnosis of chronic hemodialysis access-induced distal ischemia. J Vasc Surg. 2015; 62:135-142.

29 Beathard GA, Spergel LM. Hand ischemia associated with dialysis vascular access: An individualized access flow-based approach to therapy. Semin Dial. 2013; 26: 287-314.

30 Sousa CN, Teles P, Dias VFF, Apóstolo JLA, Figueiredo MHJS, Martins MM. Physical examination of arteriovenous fistula: The influence of professional experience in the detection of complications. Hemodial Int. 2014; 18:695-699.

31 Jaryal A, Vikrant S, Thakur P. Volkmann's ischemic contracture: An unusual complication of arterio-venous fistula. Hemodial Int. 2017; 21:E1-E3.

\section{SUPPORTING INFORMATION}

Additional supporting information may be found in the online version of this article at the publisher's web-site.

Table S1. Classification of hemodialysis access-induced distal ischaemia in four grades, analogues to the Fontaine classification of peripheral arterial occlusive disease 